\title{
Does septal-lateral annular cinching work for chronic ischemic mitral regurgitation?
}

Frederick A. Tibayan, $\mathrm{MD}^{\mathrm{a}}$

Filiberto Rodriguez, $\mathrm{MD}^{\mathrm{a}}$

Frank Langer, MD ${ }^{\mathrm{a}}$

Mary K. Zasio, BS ${ }^{\mathrm{a}}$

Lynn Bailey, $A S^{b}$

David Liang, MD, PhD

George T. Daughters, $\mathrm{MS}^{\mathrm{a}, \mathrm{c}}$

Neil B. Ingels, Jr, $\mathrm{PhD}^{\mathrm{a}, \mathrm{c}}$

D. Craig Miller, $\mathrm{MD}^{\mathrm{a}}$

From the Department of Cardiovascular and Thoracic Surgery ${ }^{\mathrm{a}}$ and Division of Cardiovascular Medicine, ${ }^{\mathrm{b}}$ Stanford University School of Medicine, Stanford, Calif, and Laboratory of Cardiovascular Physiology and Biophysics, ${ }^{\mathrm{c}}$ Research Institute, Palo Alto Medical Foundation, Palo Alto, Calif.

Read at the Twenty-ninth Annual Meeting of The Western Thoracic Surgical Association, Carlsbad, Calif, June 18-21, 2003.

Received for publication June 17, 2003; revisions requested Sept 3, 2003; accepted for publication Sept 12, 2003.

Address for reprints: D. Craig Miller, MD, Department of Cardiothoracic Surgery, Falk Cardiovascular Research Center, Stanford University School of Medicine, Stanford, CA 94305-5247 (E-mail: dcm@ stanford.edu).

J Thorac Cardiovasc Surg 2004;127:654-63 0022-5223/\$30.00

Copyright (C) 2004 by The American Association for Thoracic Surgery

doi:10.1016/j.jtcvs.2003.09.036
Objectives: Ring annuloplasty, the current treatment of choice for chronic ischemic mitral regurgitation, abolishes dynamic annular motion and immobilizes the posterior leaflet. In a model of chronic ischemic mitral regurgitation, we tested septallateral annular cinching aimed at maintaining normal annular and leaflet dynamics.

Methods: Twenty-five sheep had radiopaque markers placed on the mitral annulus and anterior and posterior mitral leaflets. A transannular suture was anchored to the midseptal mitral annulus and externalized through the midlateral mitral annulus. After 7 days, biplane cinefluoroscopy provided 3-dimensional marker data (baseline) prior to creating inferior myocardial infarction by snare occlusion of obtuse marginal branches. After 7 weeks, the 9 animals that developed chronic ischemic mitral regurgitation were restudied before and after septal-lateral annular cinching. Anterior and posterior mitral leaflet angular excursion and annular septal-lateral and commissure-commissure dimensions and percent shortening were computed.

Results: Septal-lateral annular cinching reduced septal-lateral dimension (baseline: $3.0 \pm 0.2$; chronic ischemic mitral regurgitation: $3.5 \pm 0.4[P<.05$ vs baseline by repeated measures analysis of variance and Dunnett's test]; septal-lateral annular cinching: $2.4 \pm 0.3 \mathrm{~cm}$; maximum dimension) and eliminated chronic ischemic mitral regurgitation (baseline: $0.6 \pm 0.5$; chronic ischemic mitral regurgitation: 2.3 $\pm 1.0[P<.05$ vs baseline by repeated measures analysis of variance and Dunnett's test]; septal-lateral annular cinching: $0.6 \pm 0.6$; mitral regurgitation grade [0 to $4+$ ]) but did not alter dynamic annular shortening (baseline: $7 \pm 3$; chronic ischemic mitral regurgitation: $10 \pm 5$; septal-lateral annular cinching: $6 \pm 2$, percent septallateral shortening) or posterior mitral leaflet excursion (baseline: $46^{\circ} \pm 8^{\circ}$; chronic ischemic mitral regurgitation: $41^{\circ} \pm 13^{\circ}$; septal-lateral annular cinching: $46^{\circ} \pm 8^{\circ}$ ).

Conclusions: In this model, septal-lateral annular cinching decreased chronic ischemic mitral regurgitation, reduced annular septal-lateral diameter (but not commissurecommissure diameter), and maintained normal annular and leaflet dynamics. These findings provide additional insight into the treatment of chronic ischemic mitral regurgitation.

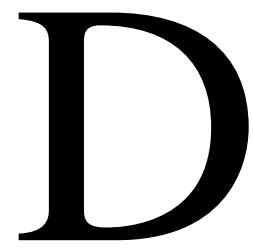

espite surgical advances, chronic ischemic mitral regurgitation (CIMR) continues to be a source of frustration for cardiac surgeons. Ring annuloplasty, the current gold standard treatment for CIMR, may achieve better results than valve replacement in selected patients, ${ }^{1}$ but rings of all types abolish normal annular dynamics $^{2,3}$ and freeze the posterior leaflet. ${ }^{4-6}$ Septal-lateral annular cinching (SLAC) is a novel approach to mitral repair that may preserve 


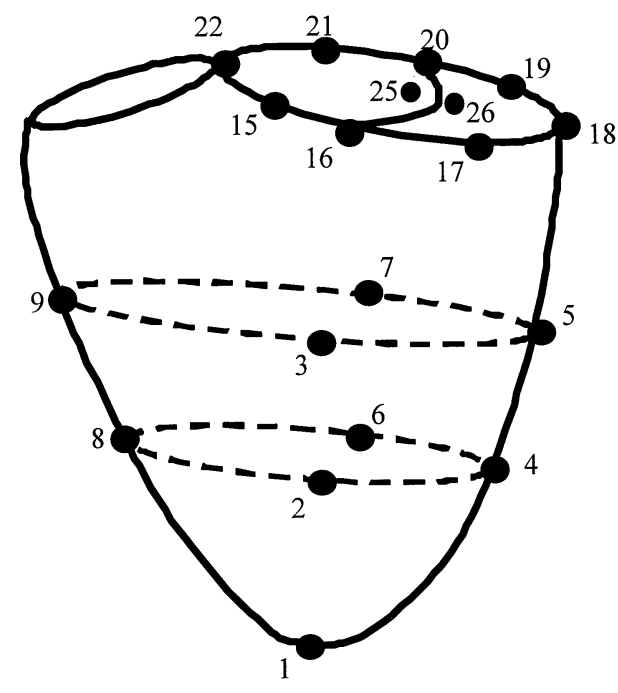

Figure 1. Schematic of marker array used in this study.

physiologic annular and leaflet dynamics. ${ }^{7}$ We tested the hypothesis that SLAC would correct CIMR while maintaining normal annular and leaflet motion in a model of CIMR.

\section{Methods}

\section{Surgical Preparation}

Twenty-five Dorsett hybrid sheep $(71 \pm 5 \mathrm{~kg}$ ) were premedicated with ketamine $(25 \mathrm{mg} / \mathrm{kg}$ intramuscularly), and anesthesia was induced with sodium thiopental $(6.8 \mathrm{mg} / \mathrm{kg}$ intravenously [IV]) and maintained with inhalational isoflurane (1\% to $2.5 \%)$. Through a left thoracotomy, 8 tantalum myocardial markers (numbered 2 through 9 in Figure 1) were inserted in the left ventricular (LV) epicardial layer along 4 equally spaced longitudinal meridians, with 1 marker at the LV apex (numbered 1 in Figure 1). Polypropylene 2-0 sutures were passed around the second and third obtuse marginal branches of the left circumflex coronary artery and loosely snared using the method of Llaneras and colleagues. ${ }^{8}$ After establishment of cardiopulmonary bypass, 8 tantalum markers were sutured around the circumference of the mitral annulus via a left atriotomy ( 1 near each commissure [numbered 16 and 20 in Figure 1] and 3 along the septal [numbered 15, 21, and 22 in Figure 1] and lateral [numbered 17, 18, and 19 in Figure 1] annuli).

The SLAC suture was placed by anchoring a single 2-0 Prolene suture (Ethicon, Inc, Somerville, NJ) to the midseptal (or anterior) annulus (annular saddle horn) and externalizing it through the midlateral (or posterior) annulus to a tourniquet on the epicardial surface (Figure 2). A micromanometer pressure transducer (PA4.5-X6; Konigsberg Instruments, Inc, Pasadena, Calif) was placed in the LV chamber through the apex. After weaning the animal from cardiopulmonary bypass, the tourniquets for the coronary artery snares and the SLAC suture were passed through the fifth intercostal space and buried in a subcutaneous pocket. Four animals died postoperatively due to respiratory complications.

\section{Experimental Protocol}

After $8 \pm 2$ days, the animals were taken to the cardiac catheterization laboratory, sedated with ketamine (1 to $4 \mathrm{mg} / \mathrm{kg} / \mathrm{h}$ IV

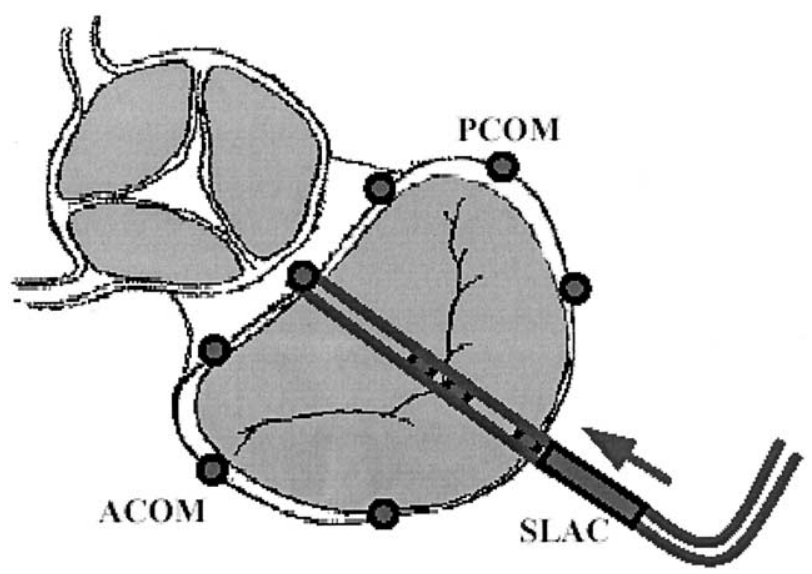

Figure 2. Schematic of septal-lateral annular cinching (SLAC) suture. A 2-0 Prolene suture was anchored to the midseptal annulus and exteriorized through the lateral annulus to an adjustable tourniquet. The anterior commissure (ACOM) and posterior commissure (PCOM) are labeled for orientation.

infusion) and diazepam (5 mg IV), intubated, mechanically ventilated, and maintained with inhalational isoflurane (1\% to $2.5 \%$ ). Transesophageal echocardiography and coronary angiography were performed and baseline biplane videofluoroscopic marker and hemodynamic data acquired ("baseline"). After premedication with lidocaine (100 mg IV), bretylium (75 mg IV), and magnesium ( 3 g IV), the coronary artery snares were tightened, and complete occlusion of the selected vessels verified by angiography. An epinephrine drip was titrated to maintain a coronary perfusion pressure (aortic diastolic pressure minus LV diastolic pressure) greater than $60 \mathrm{~mm} \mathrm{Hg}$. Ventricular arrhythmias were treated with lidocaine (50 to $100 \mathrm{mg} \mathrm{IV}$ ) and amiodarone (50 to $150 \mathrm{mg}$ IV), as needed. Nine sheep died after vessel occlusion due to refractory ventricular fibrillation. The sheep were followed for clinical signs of heart failure (tachypnea, lethargy, anorexia), and serial transthoracic echocardiography was performed to detect LV dilatation and mitral regurgitation (MR). Of the 12 remaining animals, 3 developed only trace to mild MR after 7 weeks. The 9 animals that developed significant CIMR (mean $2.3 \pm 1.0$ ) formed the final study group.

After $7 \pm 1$ weeks, the animals returned to the cardiac catheterization laboratory for recording of hemodynamic, transesophageal echocardiography (TEE), and marker data under control conditions ("CIMR") and after tightening the SLAC suture by 8 to 12 mm ("SLAC"), as illustrated in Figure 2. The MR was graded based on TEE color Doppler regurgitant jet extent and width as none $(0)$, trace $(+0.5)$, mild $(+1)$, moderate $(+2)$, moderate to severe $(+3)$, or severe $(+4)$ by an experienced echocardiographer (D.L.) in the manner described by Helmcke and colleagues, ${ }^{9}$ comparing the jet area relative to the left atrial area.

All animals received humane care in compliance with the Principles of Laboratory Animal Care formulated by the National Society for Medical Research and the Guide for Care and Use of Laboratory Animals prepared by the National Academy of Sciences and published by the National Institutes of Health (DHEW NIHG publication 85-23, revised 1985). This study was approved 
TABLE 1. Hemodynamics

\begin{tabular}{lccc}
\hline & Baseline & CIMR & SLAC \\
\hline MR (0-4+) & $0.6 \pm 0.5$ & $2.3 \pm 1.0^{*}$ & $0.6 \pm 0.6$ \\
HR (beats/s) & $101 \pm 16$ & $96 \pm 8$ & $92 \pm 11$ \\
LVEDP $(\mathrm{mm} \mathrm{Hg})$ & $12 \pm 3$ & $18 \pm 5^{*}$ & $17 \pm 5^{*}$ \\
LVPmax $(\mathrm{mm} \mathrm{Hg})$ & $93 \pm 13$ & $74 \pm 18$ & $98 \pm 17$ \\
dP/dt $(\mathrm{mm} \mathrm{Hg} / \mathrm{s})$ & $1859 \pm 690$ & $1095 \pm 549^{*}$ & $1325 \pm 355^{*}$ \\
LVEDV $(\mathrm{mL})$ & $137 \pm 32$ & $168 \pm 30^{*}$ & $162 \pm 31^{*}$ \\
LVESV $(\mathrm{mL})$ & $106 \pm 25$ & $129 \pm 22^{*}$ & $126 \pm 21^{*}$ \\
\hline
\end{tabular}

$M R$, Mitral regurgitation; $H R$, heart rate; $L V E D P$, left ventricular enddiastolic pressure; $d P / d t$, maximum time derivative of left ventricular pressure; LVPmax, maximum left ventricular pressure; $L V E D V$, left ventricular end-diastolic volume; $L V E S V$, left ventricular end-systolic volume.

${ }^{*} P<.05$ versus baseline by repeated measures ANOVA and Dunnett's test.

by the Stanford University Medical School Laboratory Research Animal Review committee and conducted according to Stanford University policy.

\section{Data Acquisition}

Images were acquired with the animal in the right lateral decubitus position with a biplane videofluoroscopy system (Philips Medical Systems, Pleasanton, Calif). Data from 2 radiographic views were digitized and merged to yield 3-dimensional (3-D) coordinates for each of the radiopaque markers every $16.7 \mathrm{~ms}$ using customdesigned software. Ascending aortic pressure, LV pressure, and electrocardiogram voltage signals were recorded simultaneously during marker data acquisition.

\section{Data Analysis}

Hemodynamics and cardiac cycle timing. Variables from 3 consecutive steady-state beats before infarction were averaged and defined as "baseline" data for each animal. Similarly, 3 beats at the follow-up study before and after cinching the SLAC suture were averaged and termed "CIMR" and "SLAC," respectively. Endsystole (ES) was defined at the time of the videofluoroscopic frame containing the point of peak negative rate of LV pressure fall $(-\mathrm{dP} / \mathrm{dt})$, and end-diastole (ED) as the videofluoroscopic frame prior to the upstroke of the LV pressure curve. Instantaneous LV volume for each frame (ie, every $16.7 \mathrm{~ms}$ ) was calculated from the positions of the epicardial LV and annular markers using a spacefilling multiple tetrahedral volume method. This method includes myocardial volume but accurately reflects changes in chamber size $^{10}$ during the cardiac cycle.

Mitral valve geometry. Mitral annular area in 3-D space was calculated for each frame throughout the cardiac cycle as the sum of the areas of 8 triangles formed by consecutive adjacent marker pairs on the annulus and the annular centroid defined from markers numbered 15 to 22 in Figure 1. For each videographic frame, septal-lateral annular diameter was calculated as the distance in 3-D space between markers placed on the midseptal and midlateral annulus (numbered 22 and 18 in Figure 1). The instantaneous commissure-commissure annular dimension was calculated as the distance between the commissural markers (numbered 16 and 20 in Figure 1). Septal-lateral annular shortening and commissure-
TABLE 2. Mitral annular dynamics

\begin{tabular}{lccc}
\hline & Baseline & CIMR & SLAC \\
\hline MAA max $\left(\mathrm{cm}^{2}\right)$ & $8.5 \pm 0.9$ & $11.6 \pm 2.1^{*}$ & $8.8 \pm 1.6$ \\
MAA min $\left(\mathrm{cm}^{2}\right)$ & $7.7 \pm 0.9$ & $10.1 \pm 2.4^{*}$ & $7.6 \pm 1.5$ \\
S-L min (cm) & $2.7 \pm 0.2$ & $3.1 \pm 0.5^{*}$ & $2.3 \pm 0.3$ \\
S-L max (cm) & $3.0 \pm 0.2$ & $3.5 \pm 0.4^{*}$ & $2.4 \pm 0.3$ \\
C-C min (cm) & $3.5 \pm 0.3$ & $3.9 \pm 0.5^{*}$ & $3.9 \pm 0.5^{*}$ \\
C-C max (cm) & $3.8 \pm 0.3$ & $4.3 \pm 0.3^{*}$ & $4.3 \pm 0.3^{*}$ \\
AML angle max (deg) & $75 \pm 8$ & $67 \pm 7$ & $78 \pm 7$ \\
AML angle min (deg) & $27 \pm 3$ & $23 \pm 6$ & $26 \pm 6$ \\
PML angle max (deg) & $95 \pm 7$ & $93 \pm 11$ & $102 \pm 5$ \\
PML angle min (deg) & $47 \pm 12$ & $47 \pm 10$ & $61 \pm 10^{*}$ \\
\hline
\end{tabular}

$M A A$, Mitral annular area; max, maximum; min, minimum; $S$ - $L$, septallateral; $C$ - $C$, commissure-commissure; $A M L$, anterior mitral leaflet; $P M L$, posterior mitral leaflet.

${ }^{*} P<.05$ versus baseline by repeated measures ANOVA and Dunnett's test.

commissure shortening were calculated as the percent change from their maximum to minimum dimensions.

Mitral leaflet geometry. To assess leaflet motion throughout the cardiac cycle, anterior mitral leaflet angle was calculated as the angle in 3-D space between the annular septal-lateral diameter (numbered 22 to 18 in Figure 1) and the chord between the midseptal annular marker and anterior leaflet edge marker (numbered 22 to 25 in Figure 1); similarly, the posterior mitral leaflet edge angle was defined as the angle between the septal-lateral diameter (numbered 18 to 22 in Figure 1) and the chord between the midlateral annulus and the posterior leaflet edge marker (numbered 18 to 26 in Figure 1). Leaflet excursion was expressed as the range (maximum to minimum angle) of the respective leaflet angles throughout the cardiac cycle.

Statistical analysis. All data are reported as mean \pm 1 standard deviation (SD), unless otherwise stated. Hemodynamic and mitral valve geometric data before (CIMR) and after SLAC tightening (SLAC) were compared to baseline using repeated measures analysis of variance (ANOVA) with Dunnett's test for multiple comparisons.

\section{Results}

Table 1 summarizes hemodynamic data for baseline, CIMR, and SLAC. CIMR was associated with more MR $(2.3 \pm 1.0$, range 1.5 to $4+)$ than baseline $(0.6 \pm 0.5$, range 0 to $1+)$, larger end-diastolic and end-systolic volumes, greater left ventricular end-diastolic pressure, and decreased $\mathrm{LV} \mathrm{dP/dt}$ and LV pressure. SLAC returned LV pressure and MR to baseline levels $(0.6 \pm 0.6$, range 0 to $1.5+)$, but $\mathrm{dP} / \mathrm{dt}$ was still lower and LV volumes still larger relative to baseline. Heart rate was unchanged by CIMR or SLAC.

Table 2 and Figure 3 summarize mitral annular dimensions for baseline, CIMR, and SLAC. CIMR was associated with increased mitral annular area, and cinching the SLAC suture returned mitral annular area to baseline. Commissure-commissure annular diameters increased with CIMR and did not change from CIMR values with SLAC. CIMR increased maximum and minimum septal-lateral diameter 


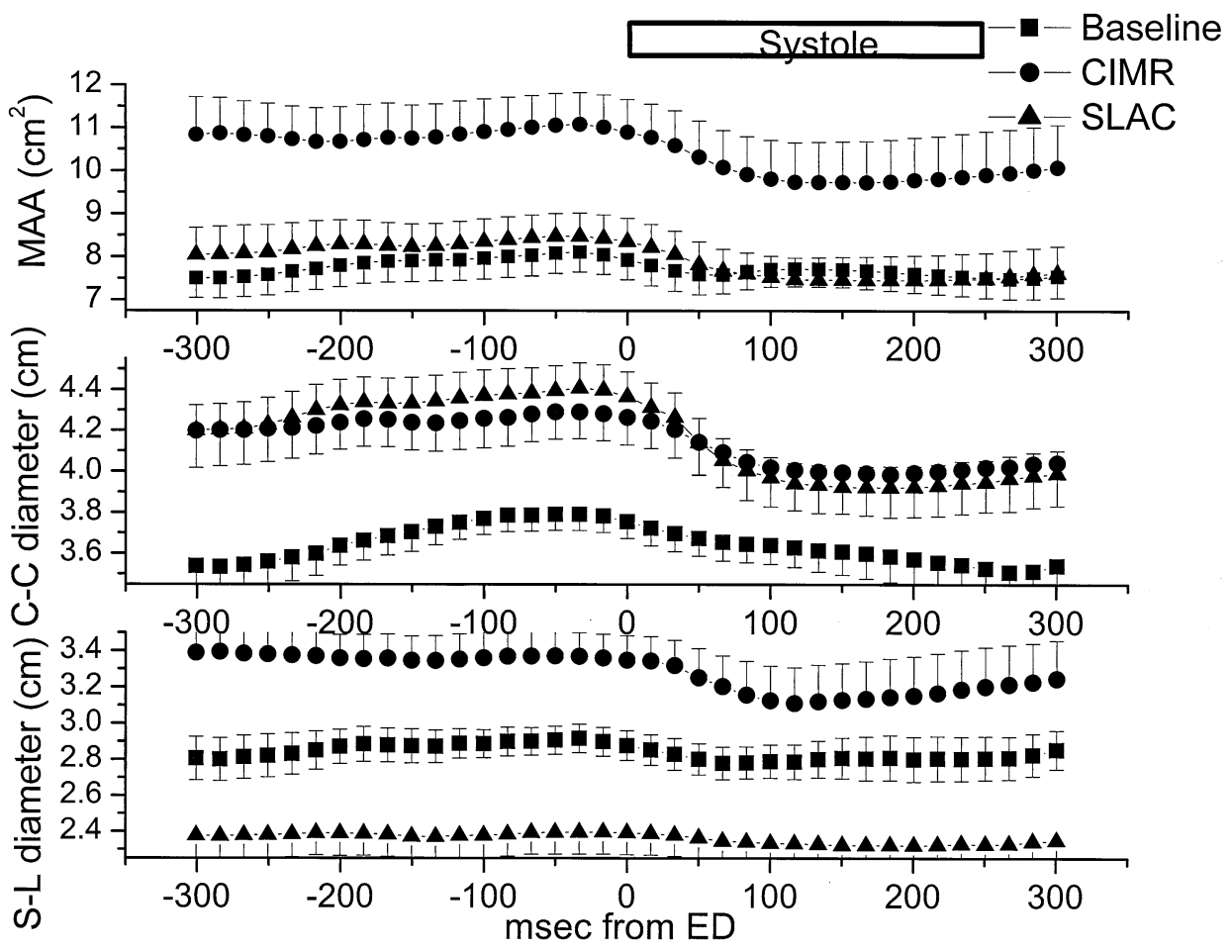

Figure 3. Mitral annular dimensions for baseline (squares), chronic ischemic mitral regurgitation (CIMR, circles) and septal-lateral annular cinching (SLAC, triangles). Top, Mitral annular area (MAA) versus time with the data centered on end-diastole (ED). Systole is indicated by the labeled bar. Middle, Commissure-commissure (C-C) annular diameter versus time with the data centered on ED. Bottom, Septal-lateral (S-L) annular diameter versus time with the data centered on ED.

from baseline; tightening the SLAC suture decreased these maximum and minimum septal-lateral diameters. Figure 4 summarizes the dynamic changes in annular dimensions for baseline, CIMR, and SLAC. Mitral annular area change, expressed as a percent, was not affected by CIMR or SLAC when compared with baseline. Similarly, percent annular shortening in the commissure-commissure direction was not altered by CIMR or SLAC. Percent annular shortening in the septal-lateral dimension for CIMR and SLAC was also similar to baseline.

Table 2 and Figure 5 summarize mitral leaflet angular motion for the baseline, CIMR, and SLAC conditions. CIMR and SLAC did not change the maximum and minimum angles of the anterior mitral leaflet relative to baseline. For the posterior mitral leaflet, CIMR had no significant effect, whereas SLAC showed a small increase in the minimum posterior mitral leaflet angle but did not significantly affect maximum angle. Figure 6 summarizes the total angular excursion of the anterior and posterior leaflets for baseline, CIMR, and SLAC. Anterior and posterior leaflet excursions were not changed after CIMR or SLAC when compared with baseline.

Figure 7 depicts mean end-systolic annular marker position at baseline, after the development of CIMR, and after
SLAC. The saddle shape of the mitral annulus was maintained after pulling on the SLAC suture.

\section{Discussion}

The results of this study support the following conclusions: (1) isolated reduction of mitral septal-lateral diameter with a transannular suture can abolish CIMR; (2) SLAC preserves physiologic annular dynamics; (3) annular reduction with SLAC preserves leaflet mobility and does not freeze the posterior mitral leaflet; (4) SLAC maintains the saddle shape of the mitral annulus.

Recently, Timek and colleagues ${ }^{7}$ introduced septal-lateral annular cinching as a novel way to abolish acute ischemic MR in an ovine model that preserved dynamic annular and leaflet motion. The primary mechanism of leaflet malcoaptation in acute ischemic MR is annular dilation leading to type I leaflet motion. ${ }^{11}$ The efficacy of SLAC in chronic ischemic MR, which involves greater subvalvular LV remodeling, is unproven. Many clinical ${ }^{12}$ and experimen$\mathrm{tal}^{13,14}$ studies have demonstrated a different pathogenesis of CIMR, in which papillary muscle displacements play a key role in leaflet tenting (systolic apical tethering, or Carpentier-type IIIb leaflet motion) and malcoaptation. ${ }^{15}$ The present study indicates that after inferior myocardial infarc- 


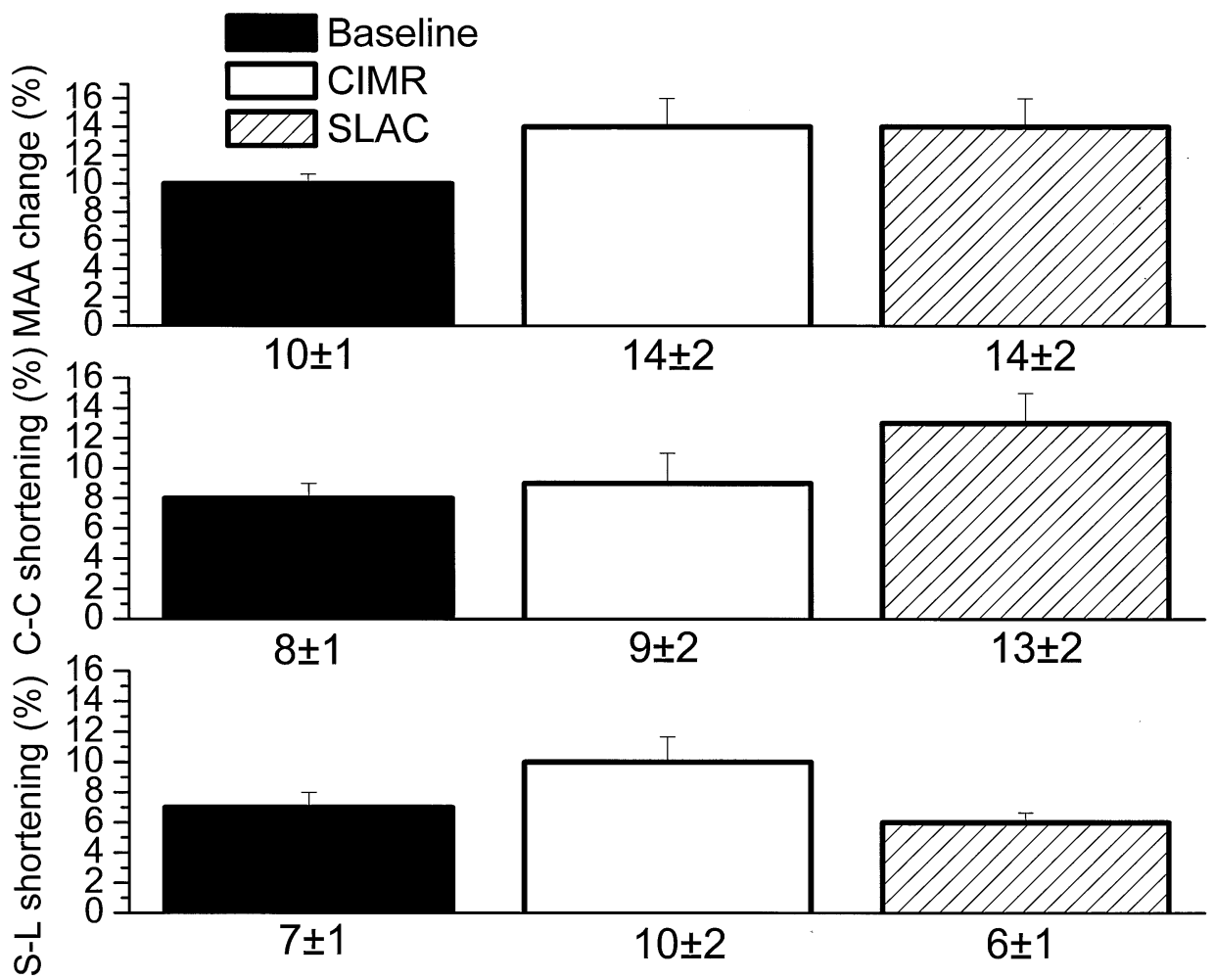

Figure 4. Mitral annular dynamics for baseline (black), chronic ischemic mitral regurgitation (CIMR, white), and septal-lateral annular cinching (SLAC, hatched) expressed as percent change from maximum to minimum (mean \pm SE). Top, Mitral annular area change in CIMR and SLAC are not different from baseline by repeated measures ANOVA and Dunnett's test. Middle, CIMR and SLAC do not change annular shortening in the commissurecommissure dimension compared to baseline. Bottom, Septal-lateral annular shortening in CIMR and SLAC is not different from baseline.

tion and the development of a substantial degree of CIMR, isolated reduction of the septal-lateral annular dimension is sufficient to restore mitral competence acutely. The annular and subvalvular components of the mitral apparatus are tightly coupled, ${ }^{16}$ however, and any intervention on the annulus will influence the geometric relationships of the annulus and papillary muscles. ${ }^{17}$ Septal-lateral reduction either with a ring ${ }^{11}$ or a transannular suture ${ }^{18}$ has been associated with very small (submillimeter) alterations in subvalvular geometry in animal studies of acute CIMR. It is possible that in addition to its direct annular effects, SLAC may have influenced the perturbed subvalvular geometry associated with CIMR. Mitral leaflet edge position is affected by both annular and papillary muscle geometry, both of which are altered in CIMR. Reduction of MR to baseline levels using SLAC was achieved only after reducing the septal-lateral annular dimension to below baseline levels. This degree of annular reduction may have been required to "drag" the posterior papillary muscle toward the septum, partially correcting the lateral displacement observed in CIMR. ${ }^{19}$ Experiments are now ongoing to elucidate the complex geometric interactions of the components of the mitral apparatus after both annular and subvalvular surgical interventions.

Although the development of CIMR was associated with commissure-commissure annular dilation, SLAC reduced MR without affecting commissure-commissure dimensions, suggesting that annular enlargement along this commissure-commissure axis is not a key factor in the pathogenesis of CIMR. This supports previous animal studies of inferior myocardial infarction ${ }^{19}$ and asymmetric annular dilation ${ }^{20}$ in which commissure-commissure dilation did not result in important mitral regurgitation. The preservation of commissure-commissure diameter after SLAC maintained mitral annular area at baseline levels. In contrast, even standard sizing of mitral annuloplasty rings results in a marked reduction of annular area, ${ }^{2}$ which has been associated with small transvalvular gradients during diastolic filling. ${ }^{21,22}$ Because the infarcted or ischemic LV myocardium in the setting of CIMR already results in diastolic dysfunction, even the small filling gradients associated with standard sized or the increasingly popular under- 


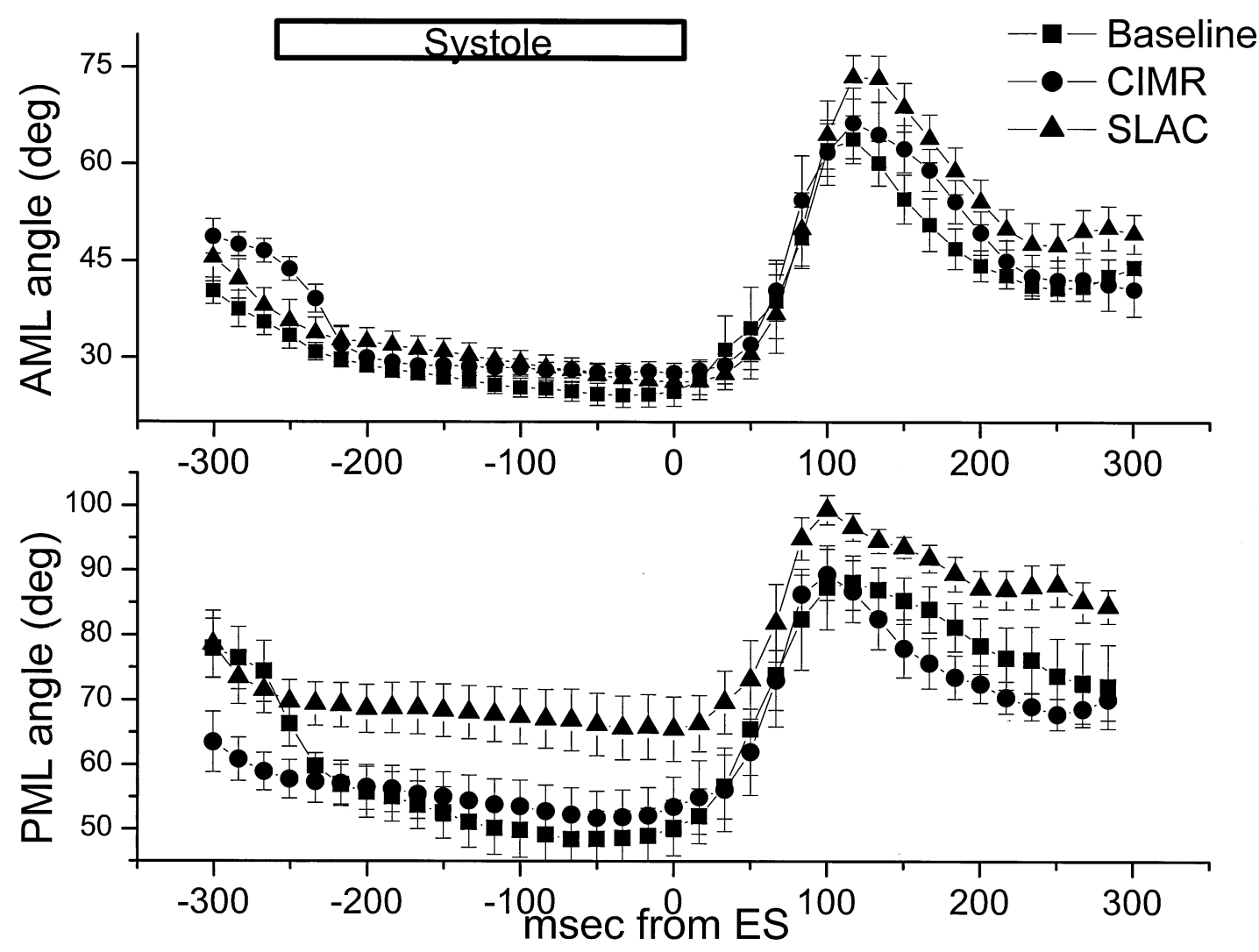

Figure 5. Mitral leaflet geometry for baseline (squares), chronic ischemic mitral regurgitation (CIMR, circles) and septal-lateral annular cinching (SLAC, triangles). Top, Anterior mitral leaflet (AML) angle versus time with the data centered on end-systole (ES). Systole is indicated by the bar on the left. Bottom, Posterior mitral leaflet (PML) angle versus time with the data centered on ES.

sized annuloplasty rings ${ }^{23}$ may add incremental insult. By maintaining orifice area, SLAC might avoid this potential problem.

Suboptimal outcomes after mitral surgery for CIMR drive the continued evolution of treatment for this challenging patient group. Chordal-sparing mitral valve replacement, ${ }^{24}$ Carpentier complete remodeling annuloplasty ring, ${ }^{25}$ flexible rings, ${ }^{26}$ partial rings, ${ }^{27}$ and suture annuloplasty $^{22}$ were all developed to preserve as much normal LV systolic function as possible. The drive to maintain more normal mitral physiology may stem from the observation that in CIMR, the valve itself is morphologically normal. Although ring annuloplasty is now the treatment of choice for CIMR, rings of all types, rigid or flexible, partial or complete, have been shown to abolish physiologic annular motion $^{2,3}$ and freeze the posterior leaflet. ${ }^{4-6}$

Preservation of annular dynamics, as observed with SLAC, may have several theoretical advantages. During systole, sphincteric contraction of the annulus likely facilitates interleaflet and interscallop coaptation. In a finite element study, Kunzelman and colleagues ${ }^{28}$ demonstrated that a loss of annular flexibility (associated with a rigid ring in their model) resulted in delayed leaflet coaptation and increased stress on the leaflets and chords. An idealized flexible ring showed normal coaptation and near-normal stress patterns in that study, ${ }^{29}$ but the authors observed, as others have demonstrated, that even flexible rings often ${ }^{3,6}$ (but not always $^{30}$ ) behave as rigid rings insofar as eliminating annular dynamics. Thus, by maintaining septal-lateral and commissure-commissure shortening during systole, SLAC may lower leaflet and chordal stresses and help to normalize leaflet closure.

During diastole, the normal increase in annular area contributes to the passive transfer of blood into the ventricle as the annulus recoils away from the LV apex toward the atrium, augmenting diastolic filling. ${ }^{31}$ Standard sizing of flexible or semi-rigid rings may reduce diastolic annular area by $30 \%$ or more, ${ }^{2}$ possibly blunting this effect. In contrast, the conserved diastolic increase in annular area after SLAC would not be expected to worsen the underlying diastolic dysfunction caused by chronic and ongoing myocardial infarction or ischemia and longstanding MR. 

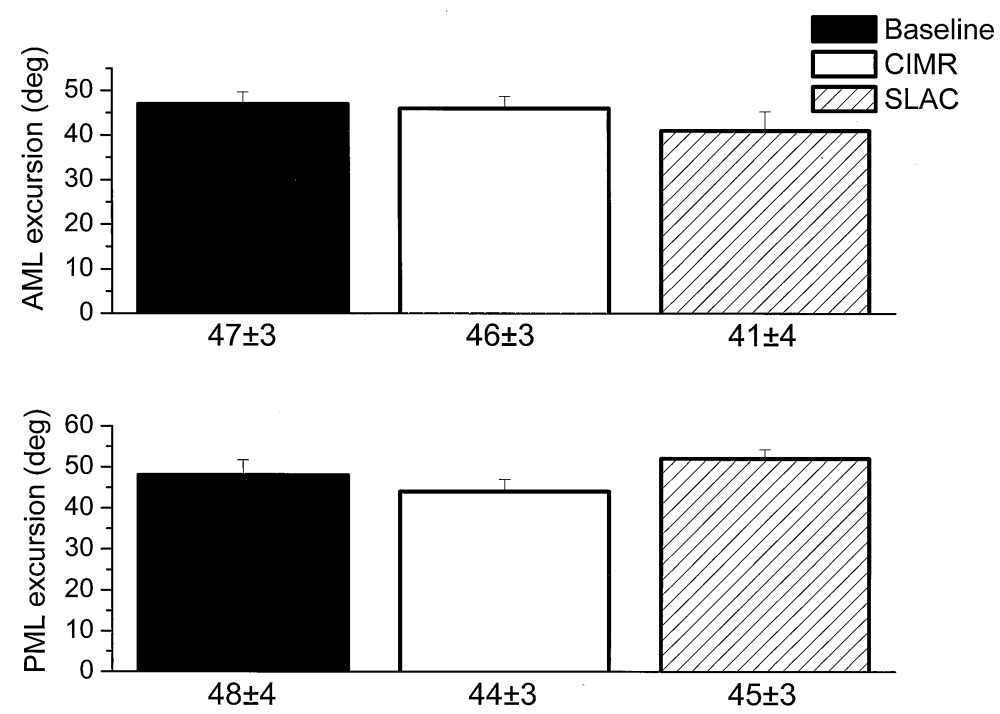

Figure 6. Mitral leaflet angular excursion for baseline (black), chronic ischemic mitral regurgitation (CIMR, white), and septal-lateral annular cinching (SLAC, hatched) expressed as percent change from maximum to minimum (mean \pm SE). Top, Anterior mitral leaflet (AML) excursion is unchanged by CIMR or SLAC compared with baseline (repeated measures ANOVA and Dunnett's test). Bottom, Posterior mitral leaflet (PML) excursion after CIMR and SLAC is not different from baseline.

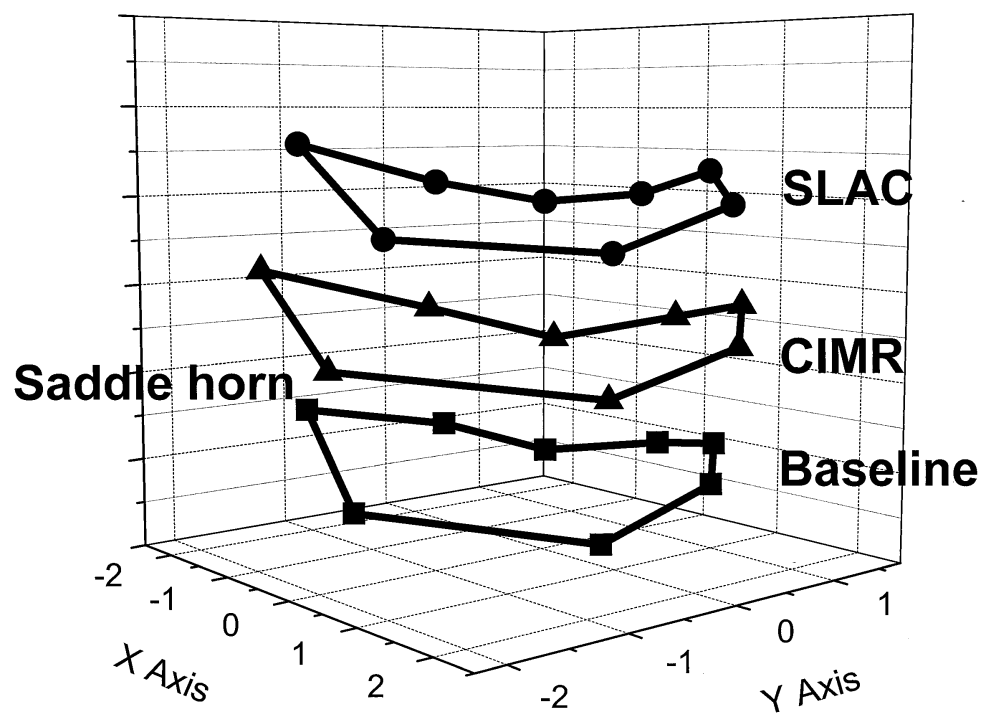

Figure 7. Average end-systolic annular marker position for baseline (bottom, squares), chronic ischemic mitral regurgitation (CIMR, middle, triangles), and septal-lateral annular cinching (top, circles). SLAC maintains the saddle shape of the annulus observed for baseline and CIMR.

In addition to damping annular dynamics, freezing of the posterior leaflet in the open position has been reported experimentally and typically observed clinically on postoperative echocardiography after implantation of rings of all types, ${ }^{4-6}$ effectively creating a functional unileaflet valve. This perturbed motion of the posterior leaflet increases the amount of annular reduction required for effective coapta- tion and may markedly alter the distribution of closing stress on the leaflets (and thus, the chordae). ${ }^{32}$ Animal models suggest that such increased stress up-regulates collagen deposition, which may thicken the leaflets and further perturb leaflet closure. ${ }^{33,34}$ SLAC did not acutely impair the mobility of either the anterior or posterior leaflets, as leaflet angular excursion was similar under all conditions. The 
small increases in maximum and minimum posterior mitral leaflet angles after SLAC are a consequence of the vertex of the posterior mitral leaflet angle, the lateral annulus, being drawn toward the septal annulus. Thus, SLAC translated the posterior leaflet angle versus time curve upward, but the amplitude was unchanged. Computer models predict that preservation of leaflet mobility (as observed with SLAC) distributes closing stresses more evenly, ${ }^{35}$ but further studies are required to confirm this hypothesis.

Three-dimensional echocardiography, ${ }^{36}$ marker fluoroscopy, ${ }^{37}$ and sonomicrometry, ${ }^{38}$ have all demonstrated the saddle shape of the mitral annulus, which contributes to leaflet curvature, theoretically reducing leaflet stress in finite element models. ${ }^{39}$ Currently available complete annuloplasty rings (except for the slightly raised anterior "hump" of the Carpentier-Edwards Physio ring, Edwards Lifesciences, Irvine, Calif) are flat when compared with the native mitral annulus and may lead to increased leaflet (and thus chordal) stress after implantation. SLAC appears to maintain the saddle shape of the annulus, which might decrease leaflet stress and reduce the possibility of longterm structural valve deterioration. ${ }^{39}$

This study used an ovine model of chronic inferior infarction, which differs from the clinical entity. All sheep had undergone opening of the pericardium, cardiopulmonary bypass, and surgical manipulation of the mitral apparatus. Also, differences in leaflet, annular, and subvalvular geometry might result in different effects of SLAC in human subjects.

The animals were killed shortly after correction of CIMR with SLAC. Thus, we have no information regarding the durability of this procedure or its long-term impact on adverse LV remodeling in CIMR. Although the suture is anchored to the fibrous skeleton of the heart, the potential for loosening or tearing of the stitch is real, especially if SLAC is used alone without an adjunctive procedure to reverse or limit further pathological annular and ventricular remodeling.

Quantitative measures of MR, such as estimated regurgitant orifice and regurgitant volume, have shown promise in studies of CIMR. ${ }^{12,13}$ In this experiment, severity of MR was graded semi-quantitatively and subjectively by jet size on a scale of 0 to $4+$ (a standard method used in clinical practice) by the same echocardiographer (D.L.). Increased separation between the esophagus and the heart in sheep relative to humans resulted in variable TEE image quality, precluding the calculation of more quantitative measures of MR. The lower grade of MR in this study compared with previous reports may stem from anatomic variations in coronary anatomy between different strains of sheep, variability in the extent of MI created due to technical differences, or possibly the use of TEE in this experiment versus transdiaphragmatic (epicardial) echocardiography at Penn, which allows better resolution but requires a laparotomy at the time of each study. ${ }^{8}$

SLAC, a novel surgical approach to CIMR, restored mitral competence acutely without perturbing physiologic annular and leaflet dynamics. Whether preservation of annular and leaflet motion using any technique translates into a more predictable or more durable mitral repair remains a question to be answered by future experimental and clinical studies. The clinical potential of this method is presently unknown, but these findings provide valuable insight in the evolving treatment of CIMR, as surgeons continuously search for better ways to restore valvular competency in a morphologically normal valve.

\section{References}

1. Gillinov AM, Wierup PN, Blackstone EH, Bishay ES, Cosgrove DM, White $\mathrm{J}$, et al. Is repair preferable to replacement for ischemic mitral regurgitation? J Thorac Cardiovasc Surg. 2001;122:1125-41.

2. Glasson JR, Green GR, Nistal JF, Dagum P, Komeda M, Daughters GT, et al. Mitral annular size and shape in sheep with annuloplasty rings. J Thorac Cardiovasc Surg. 1999;117:302-9.

3. Dagum P, Timek T, Green GR, Daughters GT, Liang D, Ingels NB Jr, et al. Three-dimensional geometric comparison of partial and complete flexible mitral annuloplasty rings. J Thorac Cardiovasc Surg. 2001; 122:665-73.

4. Green GR, Dagum P, Glasson JR, Nistal JF, Daughters GT, Ingels NB $\mathrm{Jr}$, et al. Restricted posterior leaflet motion after mitral ring annuloplasty. Ann Thorac Surg. 1999;68:2100-6.

5. Timek TA, Dagum P, Lai DT, Tibayan F, Liang D, Daughters GT, et al. Will a partial posterior annuloplasty ring prevent acute ischemic mitral regurgitation? Circulation. 2002;106(Suppl 1):I33-9.

6. Rijk-Zwikker GL, Mast F, Schipperheyn JJ, Huysmans HA, Bruschke AV. Comparison of rigid and flexible rings for annuloplasty of the porcine mitral valve. Circulation. 1990;82:IV58-64.

7. Timek TA, Lai DT, Tibayan F, Liang D, Daughters GT, Dagum P, et al. Septal-lateral annular cinching abolishes acute ischemic mitral regurgitation. J Thorac Cardiovasc Surg. 2002;123:881-8.

8. Llaneras MR, Nance ML, Streicher JT, Linden PL, Downing SW, Lima JA, et al. Pathogenesis of ischemic mitral insufficiency. J Thorac Cardiovasc Surg. 1993;105:439-42.

9. Helmcke F, Nanda NC, Hsiung MC, Soto B, Adey CK, Goyal RG, et al. Color Doppler assessment of mitral regurgitation with orthogonal planes. Circulation. 1987;75:175-83.

10. Moon MR, DeAnda A Jr, Daughters GT, Ingels NB Jr, Miller DC. Experimental evaluation of different chordal preservation methods during mitral valve replacement. Ann Thorac Surg. 1994;58:931-43.

11. Lai DT, Timek TA, Tibayan FA, Green GR, Daughters GT, Liang D, et al. The effects of mitral annuloplasty rings on mitral valve complex 3-D geometry during acute left ventricular ischemia. Eur J Cardiothorac Surg. 2002;22:808-16.

12. Yiu SF, Enriquez-Sarano M, Tribouilloy C, Seward JB, Tajik AJ. Determinants of the degree of functional mitral regurgitation in patients with systolic left ventricular dysfunction: a quantitative clinical study. Circulation. 2000;102:1400-6.

13. Otsuji Y, Handschumacher MD, Liel-Cohen N, Tanabe H, Jiang L, Schwammenthal E, et al. Mechanism of ischemic mitral regurgitation with segmental left ventricular dysfunction: three-dimensional echocardiographic studies in models of acute and chronic progressive regurgitation. J Am Coll Cardiol. 2001;37:641-8.

14. Gorman JH III, Gorman RC, Plappert T, Jackson BM, Hiramatsu Y, John-Sutton MG, et al. Infarct size and location determine development of mitral regurgitation in the sheep model. J Thorac Cardiovasc Surg. 1998;115:615-22.

15. Messas E, Guerrero JL, Handschumacher MD, Conrad C, Chow CM, Sullivan S, et al. Chordal cutting: a new therapeutic approach for ischemic mitral regurgitation. Circulation. 2001;104:1958-63. 
16. Komeda M, Glasson JR, Bolger AF, Daughters GT, Ingels NB Jr, Miller DC. Papillary muscle-left ventricular wall "complex." J Thorac Cardiovasc Surg. 1997;113:292-300.

17. Dagum P, Timek TA, Green GR, Lai D, Daughters GT, Liang DH, et al. Coordinate-free analysis of mitral valve dynamics in normal and ischemic hearts. Circulation. 2000;102(Suppl 3):III62-9.

18. Timek TA, Lai DT, Tibayan F, Liang D, Rodriguez F, Daughters GT, et al. Annular versus subvalvular approaches to acute ischemic mitral regurgitation. Circulation. 2002;106(Suppl 1):I27-32.

19. Tibayan FA, Rodriguez F, Zasio MK, Bailey L, Liang D, Daughters GT, et al. Geometric distortions of the mitral valvular-ventricular complex in chronic ischemic mitral regurgitation. Circulation. 2003; 108(Suppl 1):II116-21.

20. Green GR, Dagum P, Glasson JR, Daughters GT, Bolger AF, Foppiano LE, et al. Mitral annular dilatation and papillary muscle dislocation without mitral regurgitation in sheep. Circulation. 1999;100:II95102.

21. Borghetti V, Campana M, Scotti C, Domenighini D, Totaro P, Coletti $\mathrm{G}$, et al. Biological versus prosthetic ring in mitral-valve repair: enhancement of mitral annulus dynamics and left-ventricular function with pericardial annuloplasty at long term. Eur J Cardiothorac Surg. 2000;17:431-9.

22. Detter C, Aybek T, Kupilik N, Fischlein T, Moritz A. Mitral valve annuloplasty: comparison of the mural annulus shortening suture (MASS) with the Carpentier-Edwards prosthetic ring. J Heart Valve Dis. 2000;9:478-86.

23. Bolling SF. Mitral reconstruction in cardiomyopathy. J Heart Valve Dis. 2002;11(Suppl 1):S26-31.

24. Yun KL, Sintek CF, Miller DC, Pfeffer TA, Kochamba GS, Khonsari $\mathrm{S}$, et al. Randomized trial comparing partial versus complete chordalsparing mitral valve replacement: effects on left ventricular volume and function. $J$ Thorac Cardiovasc Surg. 2002;123:707-14.

25. Carpentier AF, Lessana A, Relland JY, Belli E, Mihaileanu S, Berrebi AJ, et al. The "physio-ring:" an advanced concept in mitral valve annuloplasty. Ann Thorac Surg. 1995;60:1177-85.

26. Duran CG, Ubago JL. Clinical and hemodynamic performance of a totally flexible prosthetic ring for atrioventricular valve reconstruction. Ann Thorac Surg. 1976;22:458-63.

27. Cosgrove DM III, Arcidi JM, Rodriguez L, Stewart WJ, Powell K, Thomas JD. Initial experience with the Cosgrove-Edwards Annuloplasty System. Ann Thorac Surg. 1995;60:499-503.

28. Kunzelman KS, Reimink MS, Cochran RP. Flexible versus rigid ring annuloplasty for mitral valve annular dilatation: a finite element model. J Heart Valve Dis. 1998;7:108-16.

29. Kunzelman KS, Reimink MS, Cochran RP. Flexible versus rigid ring annuloplasty for mitral valve annular dilatation: a finite element model. J Heart Valve Dis. 1998;7:108-16.

30. Dall'Agata A, Taams MA, Fioretti PM, Roelandt JR, Van Herwerden LA. Cosgrove-Edwards mitral ring dynamics measured with transesophageal three-dimensional echocardiography. Ann Thorac Surg. 1998;65:485-90.

31. Toumanidis ST, Sideris DA, Papamichael CM, Moulopoulos SD. The role of mitral annulus motion in left ventricular function. Acta Cardiol. 1992;47:331-48.

32. Kunzelman KS, Reimink MS, Cochran RP. Flexible versus rigid ring annuloplasty for mitral valve annular dilatation: a finite element model. J Heart Valve Dis. 1998;7:108-16.

33. Quick DW, Kunzelman KS, Kneebone JM, Cochran RP. Collagen synthesis is upregulated in mitral valves subjected to altered stress. ASAIO J. 1997;43:181-6.

34. Kunzelman KS, Quick DW, Cochran RP. Altered collagen concentration in mitral valve leaflets: biochemical and finite element analysis. Ann Thorac Surg. 1998;66:S198-205.

35. Kunzelman KS, Reimink MS, Cochran RP. Flexible versus rigid ring annuloplasty for mitral valve annular dilatation: a finite element model. J Heart Valve Dis. 1998;7:108-16.

36. Flachskampf FA, Chandra S, Gaddipatti A, Levine RA, Weyman AE, Ameling W, et al. Analysis of shape and motion of the mitral annulus in subjects with and without cardiomyopathy by echocardiographic 3-dimensional reconstruction. J Am Soc Echocardiogr. 2000;13:27787.
37. Timek TA, Dagum P, Lai DT, Liang D, Daughters GT, Ingels NB Jr, et al. Pathogenesis of mitral regurgitation in tachycardia-induced cardiomyopathy. Circulation. 2001;104(Suppl 1):I47-53.

38. Gorman RC, McCaughan JS, Ratcliffe MB, Gupta KB, Streicher JT, Ferrari VA, et al. Pathogenesis of acute ischemic mitral regurgitation in three dimensions. J Thorac Cardiovasc Surg. 1995;109:684-93.

39. Salgo IS, Gorman JH III, Gorman RC, Jackson BM, Bowen FW, Plappert $\mathrm{T}$, et al. Effect of annular shape on leaflet curvature in reducing mitral leaflet stress. Circulation. 2002;106:711-7.

\section{Discussion}

Dr Eugene Grossi (New York, NY). I want to acknowledge and congratulate Fred and his coauthors on this very important study. Tremendous efforts have gone into doing such an experiment when you realize that only one third of all the experimental surgical preparations will eventually yield data. I think it is very important to note from their data that only the septal-lateral or the AP diameter decrease is necessary to abolish ischemic MR. This data clearly shows that even with a significant increase in commissure-commissure distance (about $13 \%$ in this model), you don't need a totally circumferential remodeling device to successfully treat CIMR. For cardiac surgery cases at NYU we would advocate a semi-rigid partial remodeling device that aggressively shortens the AP diameter and permits physiologic annular dynamics, not a ring device.

Now some questions for you, Fred. We know that LV volumes remain elevated after SLAC. What happens to LV performance? What price is the ventricle paying? Although alluded to in the text it is not clear whether any LV data was available in these animals.

Dr Tibayan. Thank you, Dr Grossi, for your obviously thoughtful review of the article and your insightful comments. As far as LV performance, unfortunately we don't have any loadindependent indices of systolic function because our caval occluders that we typically use in our lab tend to fail after about a month, so we are left with load-dependent indices such as $\mathrm{dP} / \mathrm{dt}$, which I showed. What typically happened for all of those indices is that, for instance, $\mathrm{dP} / \mathrm{dt}$ rose slightly after tightening the SLAC suture but those numbers were still significantly lower than baseline. The same was true for end systolic pressure, maximum left ventricular pressure, and single beat estimates of elastins. Now all of these changes could certainly be attributed to simply getting rid of the MR. It is also possible that the septal-lateral annular cinching affected a shape change of the global ventricle, somewhat taking off on the idea popularized by Dr Bolling at the University of Michigan where an undersized annuloplasty remodels the base of the heart and perhaps unloads the myocytes. We have no data to address that issue right now. However, we just finished writing a program that will use the ventricular markers to calculate the circumferential LV radius of curvature, which may be decreased and thus reduce wall stress but we look forward to looking into that very soon.

Dr Grossi. Do you think that a single suture will have enough staying power in human tissue and do you think it can be done with an off-pump technique?

Dr Tibayan. Certainly durability is one of the most important unanswered questions with respect to the SLAC technique, and although the septal or saddle-horn stitch is anchored in the fibrous skeleton of the heart, it is certainly plausible to imagine it tearing out at some point in the future. We have no data right now looking at that but actually next month we are going to be starting exper- 
iments looking into the long-term effect of SLAC both as a stand-alone and perhaps as an adjunctive procedure and also looking into modifications of the technique, looking forward to an off-pump method of doing a similar kind of repair.

Dr Grossi. Please comment on the drastic, either $30 \%$ or $50 \%$, decrease in the septal-lateral suture length that was necessary to achieve the desired clinical effect. In off-pump ischemic MR patients in whom we are both elevating the annulus and the inferior wall using the Myocor Coapsys device, we are typically only having to decrease this distance $15 \%$ to $20 \%$. Why do you think you have to pull up so much further here to get rid of the MR than what we have to do in study patients?

Dr Tibayan. That's a very perceptive observation, Dr Grossi. I think the reason for that is because, as a lot of investigators have shown, chronic ischemic MR results not only from annular dilation but also the displacement of the papillary muscle, specifically lateral displacement of the posterior papillary muscle. I think for the SLAC to be effective it has to address not only the septallateral annular diameter but also correct at least in part this lateral posterior papillary muscle displacement because a lot of annular reduction isn't going to get you too far if the papillary muscles are still sitting out here causing leaflet tenting. So I think we had to keep cinching down until the papillary muscle was dragged in somewhat indirectly by means of mechanical continuity of the LV between the annulus and the papillary muscle. Of course the reason, as you pointed out, that the Coapsys device probably, I'm guessing, requires less annular reduction is that it has a second foot that is directly moving in the papillary muscle.

\section{UN THE MOVE?}

Don't miss a single issue of the journal! To ensure prompt service when you change your address, please photocopy and complete the form below.

Please send your change of address notification at least six weeks before your move to ensure continued service. We regret we cannot guarantee replacement of issues missed due to late notification.

\section{JOURNAL TITLE:}

Fill in the title of the journal here.

\section{OLD ADDRESS:}

Affix the address label from a recent issue of the journal here.

\section{NEW ADDRESS:}

Clearly print your new address here.

Name

Address

City/State/ZIP

\section{COPY AND MAIL THIS FORM TO:}

Elsevier Inc.

Subscription Customer Service

6277 Sea Harbor Dr

Orlando, FL 32887

\section{OR FAX TO: \\ 407-363-9661}

OR PHONE:

800-654-2452

Outside the U.S., call

407-345-4000 